\title{
Human Skin Levels of Retinoic Acid and Cytochrome P-450-derived 4-Hydroxyretinoic Acid after Topical Application of Retinoic Acid In Vivo Compared to Concentrations Required to Stimulate Retinoic Acid Receptor-mediated Transcription In Vitro
}

\author{
Elizabeth A. Duell, Anders Åström, Christopher E. M. Griffiths, Pierre Chambon, ${ }^{*}$ and John J. Voorhees \\ Department of Dermatology, University of Michigan, Ann Arbor, Michigan 48109-0528; and * Laboratorie de Génétique Moléculaire des \\ Eucaryotes du Centre National de la Recherche Scientifique U.184 Institut National de la Santé et de la Recherche Médicale, \\ Faculté de Médecine, Strasbourg, France
}

\begin{abstract}
Metabolism of retinoic acid to a less active metabolite, 4-hydroxyretinoic acid, occurs via cytochrome $P-450$ isozyme(s). Effect of a pharmacological dose of retinoic acid on the level of retinoic acid in skin and on cytochrome $P-450$ activity was investigated. $A$ cream containing $0.1 \%$ retinoic acid or cream alone was applied topically to adult human skin for four days under occlusion. Treated areas were removed by a keratome and a microsomal fraction was isolated from each biopsy. In vitro incubation of ${ }^{3} \mathrm{H}$-retinoic acid with microsomes from in vivo retinoic acid treated sites resulted in a 4.5 -fold increase $(P$ $=0.0001, n=13)$ in its transformation to 4-hydroxyretinoic acid in comparison to in vitro incubations with microsomes from in vivo cream alone treated sites. This cytochrome $\mathbf{P}-\mathbf{4 5 0}$ mediated activity was oxygen- and NADPH-dependent and was inhibited $68 \%$ by $5 \mu \mathrm{M}$ ketoconazole $(P=0.0035, n=8)$ and $51 \%$ by carbon monoxide $(P=0.02, n=6)$.

Cotransfection of individual retinoic acid receptors (RARs) or retinoid $X$ receptor- $\alpha(\mathrm{RXR}-\alpha)$ and a chloramphenicol acetyl transferase (CAT) reporter plasmid containing a retinoic acid responsive element into $\mathrm{CV}-1$ cells was used to determine the $\mathrm{ED}_{50}$ values for stimulation of CAT activity by retinoic acid and its metabolites. Levels of all trans and 13-cis RA in RAtreated tissues were greater than the $\mathrm{ED}_{\mathrm{so}}$ values determined for all three RARs with these compounds. Furthermore, the level of all trans $R A$ was greater than the $E_{50}$ for $R X R-\alpha$ whereas the 4-OH RA level was greater than the ED $_{50}$ for RAR- $\beta$ and RAR- $\gamma$ but less than for RAR- $\alpha$ and RXR- $\alpha$. These data suggest that there are sufficient amounts of retinoic acid in treated skin to activate gene transcription over both RARs and RXR- $\alpha$. (J. Clin. Invest. 1992. 90:1269-1274.) Key words: high performance liquid chromatography $\bullet$ P-450 inhibitors • reporter assay $\bullet \mathbf{E D}_{\mathbf{5 0}}$ values
\end{abstract}

This work was presented in part at the annual meeting of the Society for Investigative Dermatology, Seattle, WA, 1-4 May 1991.

Address reprint requests to Dr. Elizabeth A. Duell, Department of Dermatology, University of Michigan Medical Center, R6558 Kresge I, Box 0528, Ann Arbor, MI 48109-0528.

Received for publication 21 October 1991 and in revised form 11 February 1992.

J. Clin. Invest.

(c) The American Society for Clinical Investigation, Inc.

0021-9738/92/10/1269/06 \$2.00

Volume 90, October 1992, 1269-1274

\section{Introduction}

Retinoids such as all trans retinol ( $\mathrm{ROL})^{1}$ and all trans retinoic acid (RA) are important in epithelial proliferation and differentiation (1-3) and repair of photodamaged skin $(4,5)$. ROL is stored in tissues as retinyl esters (6-8) or bound to cellular retinol binding protein (CRBP) (3). Little or no RA is stored in tissues. Retinoids present in human skin are ROL, retinyl esters, 3,4-didehydroretinyl esters, and RA (9). RA and 3,4-didehydro RA (ddRA) act as important morphogens in the chick wing bud system either directly $(2)$ or indirectly $(10,11)$. The major retinoic acid receptor (RAR) form expressed in the epidermis is RAR- $\gamma(12,13)$. Expression of retinoid X receptor- $\alpha$ $(\mathrm{RXR}-\alpha)$ has also been demonstrated in human skin (14).

Metabolism of RA occurs via a cytochrome P-450 (P-450) mediated enzyme system in tissues such as liver (15-17), trachea (15), intestine (16), and rodent skin (18). The primary product formed is 4-OH RA which is further transformed to 4-oxo RA. Topical application of RA to skin of 4-d-old rats increases RA metabolism fourfold. In vitro ketoconazole inhibits conversion of RA to 4-OH RA by microsomes from rat epidermis (18). In liver the formation of 4-OH RA via P-450 isozyme(s) is inhibited both in vivo and in vitro by ketoconazole (19).

In this study a single topical dose of $0.1 \% \mathrm{RA}$ cream or cream vehicle was applied to adult human skin and kept under constant occlusion. After $96 \mathrm{~h}$ vehicle- and RA-treated sites were tested for their capacity to metabolize RA and were analyzed for RA and RA metabolite content. RA and its metabolites were also tested for their capacity to induce RAR- $\alpha$, RAR$\beta$, RAR- $\gamma$, or RXR- $\alpha$-mediated transcription of a reporter gene in a cotransfection system.

\section{Methods}

Isocitrate, isocitrate dehydrogenase, NADPH, NAD, 13-cis RA, and RA were purchased from Sigma Chemical Co. (St. Louis, MO). CV-1 cells, African Green Monkey kidney cells, were purchased from American Type Culture Collection (Rockville, MD). ${ }^{3} \mathrm{H}-\mathrm{RA}$ was obtained from DuPont NEN (Boston, MA) and $\left[{ }^{14} \mathrm{C}\right]$ chloramphenicol from Amersham Corp. (Arlington Heights, IL). RA metabolites 4-OH RA, 4-oxo RA, 13-cis 4-oxo RA, and 5,6-epoxy RA were gifts from Drs.

1. Abbreviations used in this paper: CAT, chloramphenicol acetyl transferase; CRBP, cellular retinol binding protein; ddRA, 3,4-didehydro retinoic acid; RA, all trans retinoic acid; RAR, RA receptor; ROL, all trans retinol; $\mathrm{RXR}-\alpha$, retinoid $\mathrm{X}$ receptor- $\alpha$. 
Michael Rosenberger and P. F. Sorter of Hoffmann-LaRoche (Nutley, $\mathrm{NJ}$ ). Metabolite 3,4-ddRA was a gift from Drs. I. Kompis and $M$. Klaus of Hoffmann-LaRoche AG (Basel, Switzerland). The 0.1\% RA $\left(\right.$ Retin- $\left.A^{\oplus}\right)$ and vehicle cream were supplied by Ortho Pharmaceutical Corp. (Raritan, NJ). HPLC grade acetonitrile and methanol were purchased from Burdick \& Jackson Laboratories Inc., a division of Baxter Products (Romulus, MI). Spherisorb ODS1 column was purchased from Phase Separations Inc. (Norwalk, CT).

$R A$ application and biopsy procedure. $0.5 \mathrm{~g}$ of RA $\left(0.1 \%\right.$ Retin- ${ }^{\star}$ cream) and $0.5 \mathrm{~g}$ of vehicle cream were applied to separately marked 3 $\times 2$ inch areas on the buttock region of adult volunteers and kept occluded for four days with Saran Wrap and secured with surgical tape (20). At four days test areas were evaluated for erythema, washed, and keratomed under $1 \%$ lidocaine local anesthesia (20). In experiments to determine RA and RA metabolite levels, all three RA-treated areas were washed with chlorhexadine soap solution. In addition, two sites were washed with ethanol and one of the ethanol plus soap-washed sites was tape-stripped to "glistening", i.e., for removal of stratum corneum, before keratoming. Epidermal samples were immediately frozen in liquid nitrogen and stored at $-80^{\circ} \mathrm{C}$ until used. Skin punch biopsies $(2 \mathrm{~mm})$ were taken from tape-stripped sites and placed in $10 \%$ neutral buffered formalin. These biopsies were processed for hematoxylin and eosin histological analysis of adequacy of stratum corneum removal by stripping. All subjects gave informed, written consent. The study was approved by the University of Michigan Medical Center Institutional Review Board.

RA metabolism assay. Microsomal fractions were prepared as previously described (21). RA and RA metabolites were kept in amber glass in darkened rooms with yellow lighting whenever possible. The rate of RA metabolism was determined by incubating $100 \mu \mathrm{g}$ microsomal protein in $0.01 \mathrm{M}$ phosphate buffer ( $\mathrm{pH} 7.4$ ) containing an NADPH regenerating system (21), and ${ }^{3} \mathrm{H}-\mathrm{RA}(1 \mu \mathrm{M}$, sp act $1 \mathrm{mCi} / 0.1 \mu \mathrm{mol})$ Samples were incubated for $15-45 \mathrm{~min}$ at $35^{\circ} \mathrm{C}$. The addition of $100 \mu \mathrm{l}$ methanol containing $100 \mu \mathrm{g} / \mathrm{ml}$ of butylated hydroxytoluene cooled to $-20^{\circ} \mathrm{C}$ terminated the reaction. After centrifugation at $1,000 \mathrm{~g}$ for 10 min, the supernatant fractions were analyzed for RA metabolites by reverse-phase HPLC and liquid scintillation spectrometry.

Ketoconazole, an inhibitor of cytochrome P-450, was incubated at $35^{\circ} \mathrm{C}$ for $10 \mathrm{~min}$ with all components of the assay present except for ${ }^{3} \mathrm{H}-\mathrm{RA}$ which was added to start the reaction. For incubations with $\mathrm{CO}$ as inhibitor, all components of the assay were present but tubes were kept on ice during $15 \mathrm{~min}$ flushing with $\mathrm{CO}$. Tubes were sealed and transferred to a $35^{\circ} \mathrm{C}$ water bath for formation of RA metabolites. Control tubes were handled in the same manner except the atmosphere was not equilibrated with $\mathrm{CO}$.

HPLC separation of retinoids. An HPLC system ( $1090 \mathrm{M}$; Hewlett Packard Co., Palo Alto, CA) containing a Spherisorb ODS1 column (Phase Separations Inc., $25 \mathrm{~cm} \times 4.6 \mathrm{~mm}$ ), a diode array detector, and chem workstation was used to separate retinoids. Mobile phases used for gradient elution of retinoids were those of Bugge et al. (22). Mobile phase $\mathrm{A}$ was acetonitrile:0.02 $\mathrm{M}$ ammonium acetate:acetic acid (1:1:0.01) and mobile phase $B$ was acetonitrile:0.2 $\mathrm{M}$ ammonium acetate:acetic acid (19:1:0.008). At the start of the run solvent A was $100 \%$ followed by a linear gradient to $30 \%$ solvent $B$ at $3 \mathrm{~min}$, a shallow gradient to $81 \%$ solvent $B$ at $38 \mathrm{~min}$, and $100 \%$ solvent B at $40 \mathrm{~min}$. The flow rate was $0.5 \mathrm{ml} / \mathrm{min}$ and the total time for the separation was 45 min. Effluent from the HPLC column flowed directly into a flowthrough scintillation spectrometer (Beta-One; Radiomatic Instruments and Chemical Co., Inc., Tampa, FL) with a computerized data capture system to determine radioactivity in each metabolite peak. The amount of metabolite formed was calculated based on the specific activity of added retinoic acid.

Extraction of retinoids from biopsy samples. Frozen keratome biopsies, each weighing $\sim 120 \mathrm{mg}$, were powdered and immediately transferred into $20 \mathrm{vol}$ of chloroform:methanol (2:1) containing tracer amounts of ${ }^{3} \mathrm{H}-\mathrm{RA}$. Retinoids were extracted with gentle mixing for 15 min followed by centrifugation at $1,000 \mathrm{~g}$ for $10 \mathrm{~min}$. Supernatant fractions were removed and saved. Pellets were reextracted with 5 vol of the same solvent. After centrifugation supernatant fractions were saved and pellets were extracted with methanol:water acidified to $\mathrm{pH}$ 3.2 (95:5). After centrifugation the three supernatant fractions were combined and were evaporated to dryness under a stream of nitrogen. Samples were resuspended in methanol for HPLC injection. Recovery of retinoids and assessment of nonenzymatic isomerization of all trans RA to 13-cis RA during extraction procedure were based on the amount of ${ }^{3} \mathrm{H}$-RA recovered as ${ }^{3} \mathrm{H}$-all trans or ${ }^{3} \mathrm{H}$-13-cis $\mathrm{RA}$ in comparison to the amount initially added as all trans ${ }^{3} \mathrm{H}-\mathrm{RA}$.

Cotransfection of $\mathrm{CV}-1$ cells and reporter assay. Procedures reported by Astrom et al. (23) were used to determine $\mathrm{ED}_{50}$ values for chloramphenicol acetyl transferase (CAT) activity by RA and RA metabolites. CV- 1 cells were cotransfected with RAR- $\alpha$, RAR- $\beta$, RAR- $\gamma$, or RXR- $\alpha$ expression vectors and the reporter plasmid TRE $\mathrm{TR}_{3}-t k$-CAT. Human RXR- $\alpha$ cDNA (24) was cloned from human skin as described (14) and subcloned into the expression vector pSVL (Pharmacia LKB Biotechnology, Inc., Piscataway, NJ) for use in the transfection assay (14). The effect of various concentrations of RA and RA metab olites $\left(10^{-11}-5 \times 10^{-4} \mathrm{M}\right)$ on CAT activity was determined as described (23).

Other methods. Statistical analyses for all assays were performed using a two-tailed paired $t$ test. Protein content was determined by the method of Lowry et al. (25) with BSA as standard.

The concentrations of retinoids in skin were calculated as follows. The biopsies were weighed before pulverization. The recovery of unlabeled material was equated to the recovery of added ${ }^{3} \mathrm{H}-\mathrm{RA}$. Calibration curves for the retinoids were stored in the HP-1090 HPLC unit. The absorption (peak area) from each sample was converted to nanograms of retinoid based on the calibration curves. The nanograms of retinoid divided by the percent recovery gave the value for total retinoid. This value was divided by the wet weight in grams to give micrograms per gram skin. $1 \mathrm{~g}$ wet $\mathrm{wt}$ of tissue was equivalent to $1 \mathrm{ml}$ of water for purposes of calculating molarity.

\section{Results}

Retention times for nonradioactive retinoid standards are shown in chromatogram depicted in Fig. $1 A$. RA metabolites separated by HPLC after in vitro incubation of ${ }^{3} \mathrm{H}-\mathrm{RA}$ with microsomal fractions obtained from biopsies treated in vivo with vehicle cream or $0.1 \%$ RA cream are shown in chromatograms depicted in Fig. $1 B$ (vehicle) and Fig. $1 C(0.1 \%$ RA). Incubation of ${ }^{3} \mathrm{H}-\mathrm{RA}$ with microsomes from RA-treated sites showed increased formation of 4-OH RA, 4-oxo-RA, and more polar metabolites in comparison to metabolites generated by microsomes from vehicle-treated sites.

Formation of RA metabolites was time (10-60 min) and protein concentration (100-400 $\mu \mathrm{g}$ ) dependent (data not shown). Data showing increased P-450 mediated RA metabolism four days after a single topical application of $0.1 \% \mathrm{RA}$ cream in comparison to vehicle cream for 13 normal volunteers are given in Fig. 2. There was a 4.5-fold $(P=0.0001)$ increase in formation of 4-OH RA $(124.4 \pm 17.4 \mathrm{pg} / \mathrm{min}$ per mg microsomal protein) by microsomes from RA-treated sites in comparison to formation of metabolites by microsomes from vehicle treated sites $(27.7 \pm 5.5 \mathrm{pg} / \mathrm{min}$ per $\mathrm{mg}$ microsomal protein). There was a 2.6 -fold increase in 4-oxo RA formation $(P=0.0003)$ and a 4.8 -fold increase in formation of more polar metabolites $(P=0.007)$ in RA-treated versus vehicle-treated areas.

Data showing inhibition of P-450 mediated activity by ketoconazole are given in Fig. 3. With biopsies from RA-treated sites as source of microsomes there was a $68 \%$ decrease in $4-\mathrm{OH}$ RA formation $(P=0.0035, n=8)$ in incubations containing 5 $\mu \mathrm{M}$ ketoconazole and ${ }^{3} \mathrm{H}-\mathrm{RA}(49.0 \pm 5.5 \mathrm{pg} / \mathrm{min}$ per $\mathrm{mg}$ micro- 

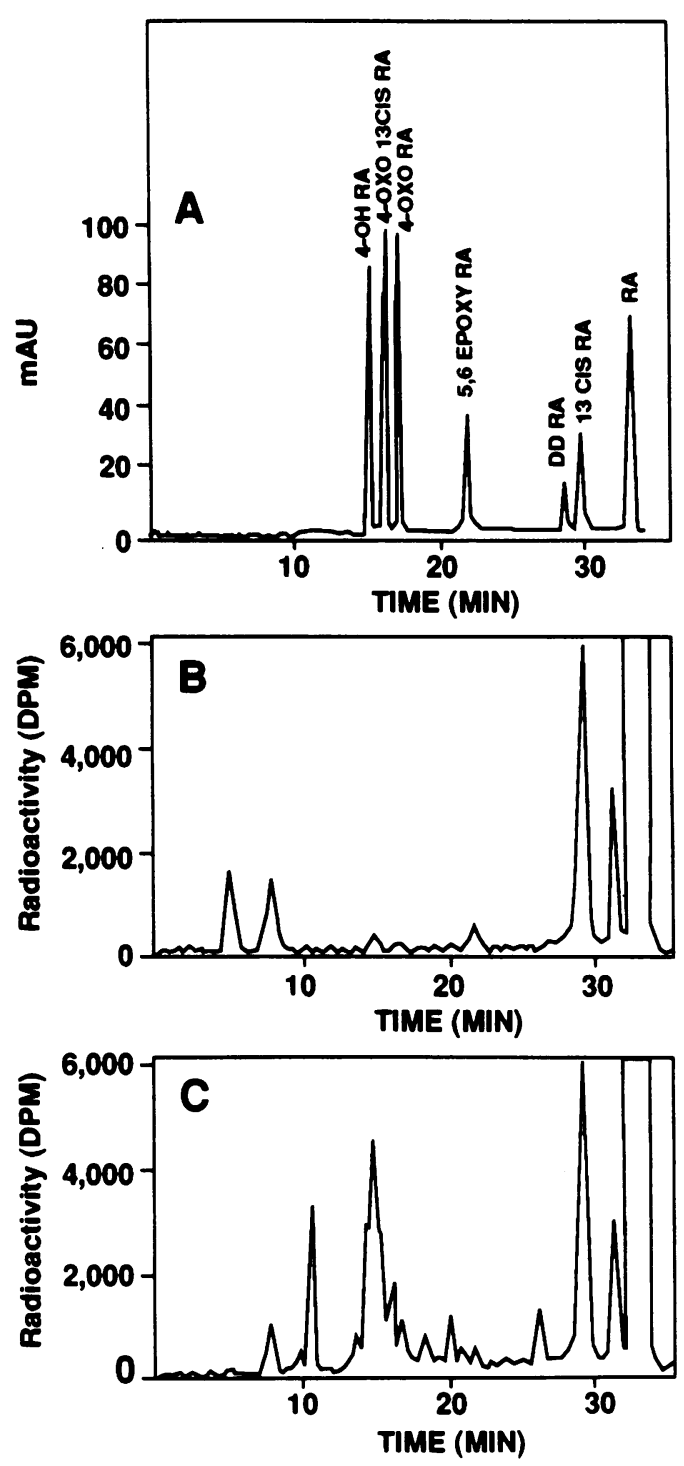

Figure 1. Reverse-phase HPLC separation of retinoids as detailed in Methods. $(A)$ Chromatogram shows retention times for nonradioactive retinoid standards. $(B)$ Depicts the chromatogram obtained after in vitro incubation of ${ }^{3} \mathrm{H}-\mathrm{RA}$ with microsomal fractions from vehicle-treated sites. $(C)$ Depicts chromatogram obtained after in vitro incubation of ${ }^{3} \mathrm{H}-\mathrm{RA}$ with microsomal fraction from RA-treated sites.

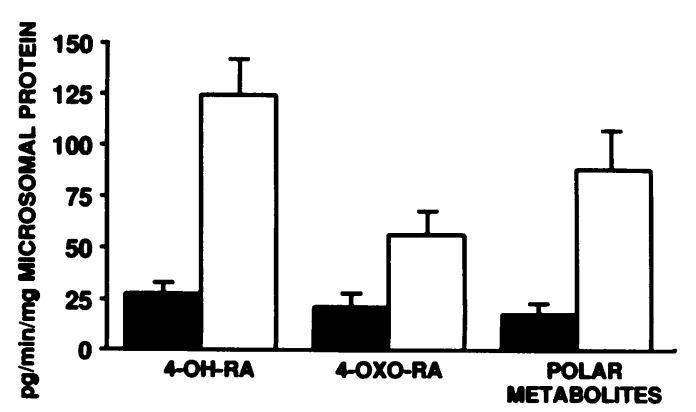

Figure 2. Retinoic acid treatment of human skin in vivo causes cytochrome P-450 mediated increased retinoic acid metabolism. In vitro assay conditions and analytical procedures are detailed in Methods. Comparison of RA-treated versus vehicle-treated sites gave the following percent increases and $P$ values: $4-\mathrm{OH}$ RA $(349 \% ; 0.0001)$, 4-oxo RA ( $162 \% ; 0.0003)$, and polar metabolites $(381 \% ; 0.007) . n$ $=13 . \pm, \mathrm{VEH} ; \square, \mathrm{RA}$.

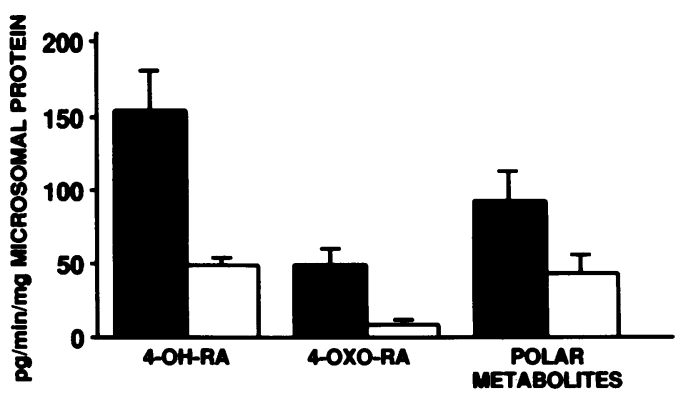

Figure 3. Ketoconazole inhibits retinoic acid-induced cytochrome $\mathrm{P}-450$-mediated transformation of retinoic acid into 4-OH retinoic acid. Conditions for in vitro assay of the microsomal fraction from RA-treated sites and analytical procedures are detailed in Methods. Comparison of ${ }^{3} \mathrm{H}-\mathrm{RA}$ versus ${ }^{3} \mathrm{H}-\mathrm{RA}+5 \mu \mathrm{M}$ ketoconazole gave the following percent decreases and $P$ values: $4-\mathrm{OH}$ RA $(68 \% ; 0.0035)$, 4-oxo RA (82\%; 0.003), and polar metabolites (53\%; 0.029). $n=8$. I, ${ }^{3} \mathrm{H}-\mathrm{RA}-1 \mu \mathrm{M}$; $\square,{ }^{3} \mathrm{H}-\mathrm{RA}+\mathrm{KETO}-5 \mu \mathrm{M}$.

somal protein) in comparison to ${ }^{3} \mathrm{H}-\mathrm{RA}$ alone $(154.1 \pm 26.2$ $\mathrm{pg} / \mathrm{min}$ per $\mathrm{mg}$ microsomal protein). There were significant decreases in formation of 4-oxo RA $(82 \%, P=0.003, n=8)$ as well as more polar metabolites $(53 \%, P=0.029, n=7)$ in incubations containing ketoconazole and ${ }^{3} \mathrm{H}-\mathrm{RA}$ in comparison to ${ }^{3} \mathrm{H}-\mathrm{RA}$ alone. As shown in Fig. 4, CO significantly decreased by $51 \%(P=0.02, n=6)$ formation of 4-OH RA.

Concentrations of retinoids required to obtain half-maximal stimulation $\left(\mathrm{ED}_{50}\right)$ of CAT activity by RAR- $\alpha$, RAR- $\beta$, RAR- $\gamma$, or RXR- $\alpha$ in cotransfected CV-1 cells are given in Table I. Data for RAR- $\gamma$, the major receptor expressed in epidermal cells, show that RA and 3,4 ddRA have an $\mathrm{ED}_{50}$ of 1-2 $\mathrm{nM}$ while 4-oxo RA requires a 10 -fold higher concentration (13 nM) and 4-OH RA a 20-fold higher concentration (30 $\mathrm{nM})$. The 5,6 epoxy RA ED $\mathrm{E}_{50}$ for RAR- $\gamma$ was $49 \mathrm{nM}$.

To determine whether concentrations of RA or its metabolites reached sufficient levels to potentially activate transcription by RARs or RXR- $\alpha$ after topical application of RA, levels of RA and its metabolites present in viable epidermis at four days were determined. Fig. 5 shows that washing the sites with soap and ethanol was not sufficient to remove RA remaining on the surface of skin. After tape stripping the amount of RA measured decreased $80 \%$ whereas 4-OH RA levels remained

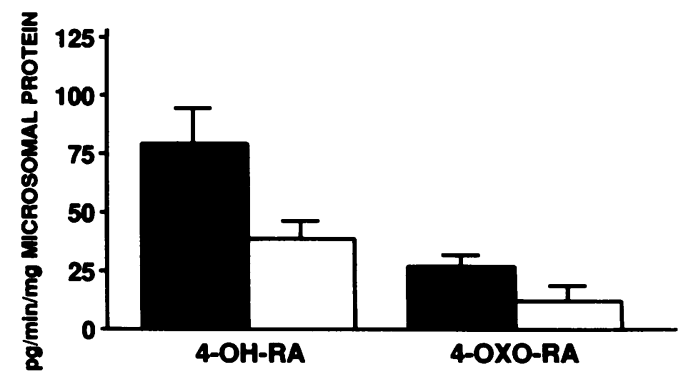

Figure 4. CO inhibits cytochrome P-450-mediated retinoic acid metabolism into 4-OH retinoic acid. Microsomal fractions from sites treated in vivo with $0.1 \%$ RA cream were used in in vitro incubations. Assay conditions and analytical procedures are detailed in Methods. A comparison of incubation with $\mathrm{RA}+\mathrm{CO}$ versus $\mathrm{RA}$ alone gave the following percent decreases and $P$ values: 4-OH RA $(51 \% ; 0.02)$ and 4-oxo RA ( 53\%; 0.07). $n=6 . \backsim,{ }^{3} \mathrm{H}-\mathrm{RA}-1 \mu \mathrm{M} ; \square,{ }^{3} \mathrm{H}-\mathrm{RA}+\mathrm{CO}$ $-1 \mu \mathrm{M}$. 
Table I. Concentrations of Retinoids Required to Obtain HalfMaximal Stimulation ( $\left.E D_{50}\right)$ of TRE $E_{3}-t k-C A T$ Transcription by Retinoic Acid Receptors and RXR- $\alpha$ Cotransfected into $C V-1$ Cells

\begin{tabular}{lrrrr}
\hline & \multicolumn{5}{c}{ ED $_{\text {so }}$} \\
\cline { 2 - 5 } Compounds & RAR- $\alpha$ & RAR- $\beta$ & RAR- $\gamma$ & RXR- $\alpha$ \\
\hline & \multicolumn{5}{c}{$n M$} \\
Retinoic Acid & $24^{*}$ & $4^{*}$ & $1.3^{*}$ & 236 \\
dd-Retinoic Acid & 34 & 13 & 1.8 & 245 \\
4-oxo-Retinoic Acid & 79 & 28 & 13 & 377 \\
4-OH Retinoic Acid & 500 & 75 & 30 & $>500$ \\
5,6-Epoxy Retinoic Acid & 237 & 56 & 49 & $>500$ \\
& & & & \\
\hline
\end{tabular}

Data represent the average value for two to three titrations from $10^{-11}$ to $5 \times 10^{-4} \mathrm{M}$ retinoid concentrations. ${ }^{*}$ These data points for $\mathrm{RA}$ were previously published (23) and are included to facilitate comparison to metabolite data.

the same regardless of the method of tissue preparation. All trans and 13-cis RA were present in almost equal amounts. The 13-cis RA present in tissue was not due to nonenzymatic isomerization during extraction since $91.2 \% \pm 1.7 \%$ of the ${ }^{3} \mathrm{H}$ RA added as tracer to determine recovery of material remained as all trans and $8.8 \% \pm 1.1 \%$ was 13 -cis RA. As shown in Table II, all trans RA was present as $824 \mathrm{ng} / \mathrm{gm}$ wet wt or $\sim 2.75 \mu \mathrm{M}$ concentration (three log units higher than the $\mathrm{ED}_{50}$ for RAR$\gamma), 13$ cis-RA as $745 \mathrm{ng} / \mathrm{gm}$ wet wt or $\sim 2.5 \mu \mathrm{M}\left(60 \times \mathrm{ED}_{50}\right.$ value for RAR- $\gamma$ ), and 4-OH RA as $93 \mathrm{ng} / \mathrm{gm}$ wet wt or $\sim 0.3$ $\mu \mathrm{M}$ concentration $\left(10 \times \mathrm{ED}_{50}\right.$ value for RAR- $\gamma$ ). 4-Oxo RA was not detected in RA-treated biopsies even though epidermal microsomes from similar biopsies showed conversion to both 4-OH and 4-oxo RA.

\section{Discussion}

The effects of daily application of RA without occlusion to photodamaged skin have been investigated in clinical studies $(4,5)$. The improvement seen is variable and dose dependent $(4,5)$. Pilot studies with $0.1 \%$ RA cream with or without occlusion used topically for various periods of time showed that RA under occlusion for four days gave a highly consistent erythematous reaction as well as characteristic histological (20) re-

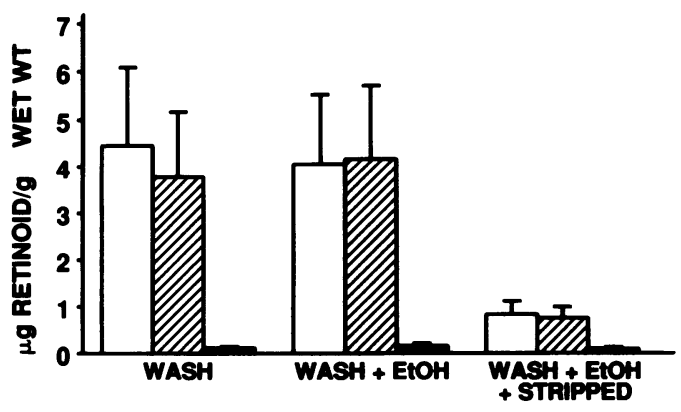

Figure 5. Retinoid content in areas treated four days with $0.1 \% \mathrm{RA}$ cream followed by removal of surface RA by the indicated methods. Extraction procedure detailed in Methods. Concentrations in stripped tissue samples were all trans $\mathrm{RA}(\approx 2.7 \mu \mathrm{M}), 13$ cis-RA $(\approx 2.5 \mu \mathrm{M})$, and 4-OH RA $(\approx 0.3 \mu \mathrm{M}), n=5$ for each method of surface RA removal. $\square$, all trans $\mathrm{RA}$;, $13-$ cis $\mathrm{RA}$; $\mathbf{\bullet}$, 4-OH RA.
Table II. Comparison of Tissue Levels after Topical Application of All Trans Retinoic Acid to Human Skin In Vivo with $E D_{\text {so }}$ Values for Transcriptional Activation of TRE $E_{3}-t k-C A T$ in a Cotransfection Assay

\begin{tabular}{llll}
\hline & all trans $\mathrm{RA}$ & 13-cis $\mathrm{RA}$ & 4-OH RA \\
\hline $\mathrm{ng} / \mathrm{g}$ wet wt & $824 \pm 281$ & $745 \pm 24$ & $93 \pm 36$ \\
$\mathrm{nM}$ & $\approx 2750$ & $\approx 2480$ & $\approx 310$
\end{tabular}

Retinoid ( $n M)$

$\begin{array}{lcrr}\text { ED }_{50} \text { RAR }-\alpha & 24^{*} & 190^{*} & >500 \\ \text { ED }_{50} \text { RAR }-\beta & 4^{*} & 43^{*} & 75 \\ \text { ED } & 1.3^{*} \text { RAR- } \gamma & 140^{*} & 30 \\ \text { ED }_{50} \text { RXR- } \alpha & 236 & \text { ND } & >500\end{array}$

* These data points were previously published (23) and are included for facilitating comparisons.

sponse in 9 of 10 patients. Because of this consistent retinoid response, the four day occluded patch was used in the current study. Routine nonoccluded clinical use of RA cream produced an inconsistent retinoid response too variable for experimentation.

In the present study a single topical application of RA with occlusion continuously for four days to adult human skin resulted in sufficient retinoic acid penetration into viable layers of the epidermis to induce RA metabolism. Our data and that of others (18) suggest that this increased metabolism is probably due to increased P-450 activity. Furthermore, induction of P-450 activity in response to RA has been reported in other tissues (15-19). In addition, 5,6 epoxy RA can be formed either by a lipid peroxidase (26) or a P-450-mediated activity (27). However, the P-450 isozyme(s) induced in human skin in response to topical RA is unknown.

P-450 enzymes purified from rabbit liver have been evaluated for their capacity to metabolize RA. IA2 and IIB4 isozymes were most effective in metabolizing RA to 4-OH RA while IIC3, IIE1, IIG2, and IIE2 were relatively ineffective, and isozymes IA1 and IIIA6 were ineffective (28).

Cultured human keratinocytes have been shown to contain the mRNA for P-450 isozyme IA1 (29). However, the IA1 isozyme was one of two forms from rabbit liver that did not metabolize RA. An immunohistochemical study of cultured human epidermal foreskin keratinocytes showed binding of monoclonal antibodies to isozymes belonging to families II and III (30). In neonatal rats topical application of 3-methylcholanthrene was more effective than topical application of RA in inducing RA metabolism by P-450 isozyme(s) (18). Phenobarbitol was the least effective inducer of RA metabolism (18). In hamsters intraperitoneal injection of methylcholanthrene increased RA metabolism in liver twofold while orally given RA increased RA metabolism eightfold in liver (16). Thus metabolism of RA in response to inducers of P-450 activity may vary as a result of route of administration, species involved, or tissue studied.

Cytochrome P-450 mediated metabolism of RA may be a significant mechanism for regulation of pharmacological RA levels in vivo. In fact the conversion of RA to less active metabolites (i.e., 4-OH and 4-oxo RA) could limit the biological activity of pharmacological doses. Whether a P-450 activity 
attenuates physiologically relevant, endogenous RA levels can not be addressed with the data presented here. However, our results do demonstrate that topical application of pharmacological doses of RA in humans induce a 4.5-fold increase in metabolism of RA to 4-OH RA and more polar metabolites. Ketoconazole, a topical antifungal agent currently in routine clinical use, is an inhibitor of some P-450 mediated activities. Ketoconazole at concentrations of $7 \times 10^{-7} \mathrm{M}$ to $5 \times 10^{-6} \mathrm{M}$ inhibits in vitro RA metabolism by rat epidermal microsomes. Similar concentrations are required to suppress certain P-450 dependent reactions in steroid synthesis (19). One possible side effect of ketoconazole use is increased RA levels due to decreased RA metabolism. This may be of clinical importance in as much as simultaneous use of topical ketoconazole and RA could decrease the amount of RA required to obtain clinical efficacy.

To determine the potency of ddRA and RA metabolites in comparison to RA and 13-cis RA in RAR- and RXR-mediated transcriptional activation, a reporter gene $\left(\mathrm{TRE}_{3}-t k\right.$ CAT) was cotransfected together with receptor expression vectors into CV-1 cells and concentrations required to obtain halfmaximal induction of CAT activity $\left(\mathrm{ED}_{50}\right)$ were determined. Similar reporter assay systems have been established with cell lines other than CV-1 cells. The $E D_{50}$ s observed for RA in these systems vary with RAR receptor type rather than the cell line used for cotransfection procedure $(23,24)$. The CV-1 cells used in the reporter assay are epithelial cells but the appropriateness of any in vitro system to in vivo occurrences is always open to question.

Of the three known RARs, RAR- $\gamma$ is the major expressed form in human skin $(12,13)$ and in the reporter assay system used in these experiments RAR- $\gamma$ has the lowest $\mathrm{ED}_{50}$ for all trans RA (1.3 $\mathrm{nM})(23)$, all trans ddRA (1.8 $\mathrm{nM})$, all trans 4-oxo-RA (13 nM), and all trans 4-OH RA ( $30 \mathrm{nM})$. The $\mathrm{ED}_{50}$ values are two- to fourfold higher for RAR- $\beta$ than those determined for RAR- $\gamma$ except for all trans ddRA which is seven times higher. The $\mathrm{ED}_{50}$ values for RAR- $\alpha$ were the highest obtained with any of the three RARs. The $\mathrm{ED}_{50}$ values for all trans RA (23) and all trans ddRA with RAR- $\alpha$ was similar to the value obtained with 4-OH RA and RAR- $\gamma(30 \mathrm{nM})$. The $\mathrm{ED}_{50}$ of 4-OH RA for RAR- $\alpha$ was similar to that of RXR- $\alpha$ $(>500 \mathrm{nM})$. RXR- $\alpha$ has been shown to be expressed in skin in vivo (14) but demonstrates higher $\mathrm{ED}_{50}$ values for all compounds tested compared to RARs. The $\mathrm{ED}_{50} \mathrm{~s}$ in the presence of RXR- $\alpha$ are 20 times higher for each compound in comparison to values for RAR- $\gamma$. The lowest $E_{50}$ for $13-$ cis $\mathrm{RA}$ is $43 \mathrm{nM}$ with RAR- $\beta$ receptor (23). The value for 13-cis RA with RAR$\gamma$ is $140 \mathrm{nM}(23)$ (Table II).

To determine whether metabolites might play a significant role in retinoid effects observed following topical application of RA, treated sites were analyzed for presence of RA and RA metabolites. Washing with soap and ethanol was not sufficient to remove RA still present on the surface and within stratum corneum of skin as evidenced by $\sim 4 \mu \mathrm{g}$ RA per g wet wt ( 12 $\mu \mathrm{M})$ in the specimen. Removal of stratum corneum and surface RA with tape stripping reduced these values to $1.5 \mu \mathrm{g} \mathrm{RA}$ per $\mathrm{g}$ wet wt $(5 \mu \mathrm{M})$. The method of preparing the site for biopsy did not change the level of 4-OH RA $(93 \mathrm{ng} / \mathrm{g}$ wet wt, $0.3 \mu \mathrm{M})$. This suggests that the presence of 4-OH RA indicates increased RA content and increased metabolism of RA within living layers of epidermis without necessitating tape stripping of skin to determine RA metabolism.
In tape-stripped biopsy samples, 53\% of RA extracted was all trans $\mathrm{RA}(2.7 \mu \mathrm{M})$ and $47 \%$ was 13 -cis $\mathrm{RA}(2.5 \mu \mathrm{M})$. This concentration of all trans RA is 2,000 times higher than the $\mathrm{ED}_{50}$ for RAR- $\gamma$ and 50-fold higher than the $\mathrm{ED}_{50}$ for RXR- $\alpha$ in the cotransfection assay. The high levels of extracted 13-cis RA after topical application of all trans RA and apparent lack of significant nonenzymatic isomerization during retinoid extraction from tissue suggests that epidermis may contain an active RA isomerase. The amount of 13-cis RA in these samples is 10 -fold higher than the $\mathrm{ED}_{50} \mathrm{~s}$ in the reporter assay of 140 $\mathrm{nM}$ with RAR- $\gamma$ and $190 \mathrm{nM}$ with RAR- $\alpha$ and 50-fold higher than the $\mathrm{ED}_{50}$ of $43 \mathrm{nM}$ for RAR- $\beta$ (23). The 4-OH RA levels were 10 times higher than the $E_{50}$ determined for RAR- $\gamma$ and four times higher than the $E_{50}$ for RAR- $\beta$ but less than the $\mathrm{ED}_{50}$ of $>500 \mathrm{nM}$ with RAR- $\alpha$ and RXR- $\alpha$ in the cotransfection assay.

The above comparisons are made on the assumption that concentrations of retinoids in skin have functional activity similar to that observed when the same retinoids are added to cell cultures containing genetically engineered retinoid response systems. However, there may be unrecognized differences between in vivo and in vitro cell penetration, distribution, and metabolism.

In conclusion, the effects observed clinically after topical application of pharmacological doses of all trans RA under occlusion for four days may be due in part to all trans RA and 13-cis RA as well as 4-OH RA. The large quantity of all trans RA as well as lesser but substantial amounts of 13-cis and 4-OH RA in relation to the concentration required for halfmaximal activation of transcription in the cotransfection assay suggests that the biological response of skin (20) in response to RA under short-term occlusion may be mediated at least in part by both RARs and RXR- $\alpha$. Whether molecular changes in skin in response to RA application can be mediated by RARand RXR- $\alpha$-independent mechanisms remains unknown.

\section{Acknowledgments}

We wish to thank Ulrika Pettersson for excellent technical assistance in the reporter gene assay, Robin Gardner for providing biopsy materials, and Ted Hamilton for statistical analyses.

This study was supported in part by a grant from R. W. Johnson Pharmaceutical Research Institute and the Babcock Endowment.

\section{References}

1. Roberts, A. B., and M. B. Sporn. 1984. Cellular biology and biochemistry of the retinoids. In The Retinoids. M. B. Sporn, A. B. Roberts, and D. S. Goodman, editors. Academic Press, New York. Vol. 2, 209-286.

2. Thaller, C., and G. Eichele. 1990. Isolation of 3,4-didehydroretinoic acid, a novel morphogenetic signal in the chick wing bud. Nature (Lond.). 345:815-819.

3. Dolle, P., E. Ruberte, P. Leroy, G. Morriss-Kay, and P. Chambon. 1990. Retinoic acid receptors and cellular retinoid binding proteins. 1. A systematic study of their differential pattern of transcription during mouse organogenesis. Development (Camb.). 110:1133-1151.

4. Weiss, J. S., C. N. Ellis, J. T. Headington, T. Tincoff, T. A. Hamilton, and J. J. Voorhees. 1988. Topical tretinoin improves photodamaged skin: a double blind vehicle-controlled study. JAMA (J. Am. Med. Assoc.). 259:527-532.

5. Weinstein, G. D., T. P. Nigra, P. E. Pochi, R. C. Savin, A. Allan, K. Benik, E. Jeffes, L. Lufrano, and G. Thorne. 1991. Topical tretinoin for treatment of photodamaged skin. Arch. Dermatol. 127:659-665.

6. Shingleton, J. L., M. K. Skinner, and D. E. Ong. 1989. Retinol esterification in Sertoli cells by lecithin-retinol acyltransferase. Biochemistry. 28:9647-9653.

7. Torma, H., and A. Vahlquist. 1987. Retinol esterification by mouse epidermal microsomes: evidence for acyl-CoA:retinol acyltransferase activity. J. Invest. Dermatol. 88:398-402. 
8. Torma, H., and A. Vahlquist. 1990. Vitamin A esterification in human epidermis: a relation to keratinocyte differentiation. J. Invest. Dermatol. 94:132138.

9. Vahlquist, A. 1982. Vitamin A in human skin. I. Detection and identification of retinoids in normal epidermis. J. Invest. Dermatol. 79:89-93.

10. Wanek, N., D. M. Gardiner, K. Muneoka, and S. V. Bryant. 1991. Conversion by retinoic acid of anterior cells into ZPA cells in the chick wing bud. Nature (Lond.). 350:81-83.

11. Noji, S., T. Nohno, E Koyama, K. Muto, K. Ohyama, Y. Aoki, K Tamura, K. Ohsugi, H. Ide, S. Taniguchi, and T. Saito. 1991. Retinoic acid induces polarizing activity but is unlikely to be a morphogen in the chick limb bud. Nature (Lond.). 350:83-86.

12. Krust, A., P. H. Kastner, M. Petkovich, A. Zelent, and P. Chambon. 1989. A third human retinoic acid receptor, hRAR- . Proc. Natl. Acad. Sci. USA. 86:5310-5314

13. Elder, J. T., G. J. Fisher, Q. Y. Zhang, D. Eisen, A. Krust, P. Kastner, P. Chambon, and J. J. Voorhees. 1991. Retinoic acid receptor gene expression in human skin. J. Invest. Dermatol. 96:425-433.

14. Elder, J. T., A. Astrom, U. Pettersson, A. Krust, P. Kastner, P. Chambon, and J. J. Voorhees. 1992. Differential regulation of retinoic acid receptors and binding proteins in human skin. J. Invest. Dermatol. 98:673-679.

15. Frolik, C. A., A. B. Roberts, T. E. Tavela, P. P. Roller, D. L. Newton, and M. B. Sporn. 1979. Isolation and identification of 4-hydroxy- and 4-oxoretinoic acid. In vitro metabolites of all-trans-retinoic acid in hamster trachea and liver. Biochemistry. 18:2092-2097.

16. Roberts, A. B., M. D. Nichols, D. L. Newton, and M. B. Sporn. 1979. In vitro metabolism of retinoic acid in hamster intestine and liver. J. Biol. Chem. 254:6296-6302.

17. Leo, M. A., S. Iida, and C. S. Lieber. 1984. Retinoic acid metabolism by a system reconstituted with cytochrome P-450. Arch. Biochem. Biophys. 234:305312.

18. Vanden Bossche, H., G. Willemsens, and P. A. J. Janssen. 1988. Cytochrome P-450-dependent metabolism of retinoic acid in rat skin microsomes: inhibition by ketoconazole. Skin Pharmacol. 1:176-185.

19. Van Wauwe, J. P., M. C. Coene, J. Goossens, G. Van Nijen, W. Cools, and W. Lauwers. 1988. Ketoconazole inhibits the in vitro and in vivo metabolism of all-trans-retinoic acid. J. Pharm. Exp. Ther. 245:718-722.
20. Fisher, G. J., J. Esmann, C. E. M. Griffiths, H. S. Talwar, E. A. Duell, C. Hammerberg, J. T. Elder, L. J. Finkel, G. D. Karabin, B. J. Nickoloff, et al. 1991. Cellular, immunologic and biochemical characterization of topical retinoic acidtreated human skin. J. Invest. Dermatol. 96:699-707.

21. Duell, E., V. Fischer, G. Fisher, A. Astrom, and J. Voorhees. 1991. Cyclosporine A metabolism by cytochrome P-450III occurs in microsomes from rat liver but not from normal epidermis or psoriatic lesions. J. Invest. Dermatol. 96:827-831.

22. Bugge, C. J. L., L. C. Rodriguez, and F. M. Vane. 1985. Determination of isotretinoin or etretinate and their major metabolites in human blood by reversed-phase high-performance liquid chromatography. J. Pharm. Biomed. Anal. 3:269-277.

23. Astrom, A., U. Pettersson, A. Krust, P. Chambon, and J. J. Voorhees. 1990. Retinoic acid and synthetic analogs differentially activate retinoic acid receptor dependent transcription. Biochem. Biophys. Res. Commun. 173:339345.

24. Mangelsdorf, D. J., E. S. Ong, J. A. Dyck, and R. M. Evans. 1990. Nuclear receptor that identifies a novel retinoic acid response pathway. Nature (Lond.) 345:224-229.

25. Lowry, O. H., N. J. Rosebrough, A. L. Farr, and R. J. Randall. 1951. Protein measurements with the Folin phenol reagent. J. Biol. Chem. 193:265275.

26. Sietsema, W. K., and H. F. DeLuca. 1982. Retinoic acid 5,6-epoxidase. J. Biol. Chem. 257:4265-4270.

27. Watabe, T., and T. Sawahata. 1979. Biotransformation of cholesterol to cholestane- $3 \beta, 5 \alpha, 6 \beta$-triol via cholesterol $\alpha$-epoxide $(5 \alpha, 6 \alpha$-epoxycholestan- $3 \beta$ ol) in bovine adrenal cortex. J. Biol. Chem. 254:3854-3860.

28. Roberts, E. S., A. D. N. Vaz, and M. J. Coon. 1991. Metabolism of retinoids by rabbit P-450 cytochromes. FASEB (Fed. Am. Soc. Exp. Biol.) J. 5:1514a. (Abstr.).

29. Berghard, A., K. Gradin, and R. Toftgard. 1990. Serum and extracellular calcium modulate induction of cytochrome P-450IA 1 in human keratinocytes. $J$. Biol. Chem. 265:21086-21090.

30. Van Pelt, F. N. A. M., Y. J. M. Olde Meierink, B. J. Blaauboer, and P. J. J. M. Weterings. 1990. Immunohistochemical detection of cytochrome $\mathrm{P}-450$ isozymes in cultured human epidermal cells. J. Histochem. Cytochem. 38:1847-1851. 